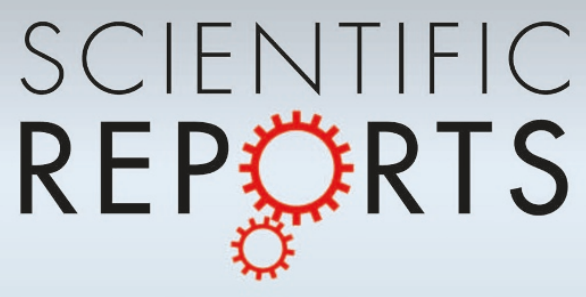

OPEN

SUBJECT AREAS:

PALAEONTOLOGY

GEOLOGY

MICROBIAL ECOLOGY

ASTEROIDS, COMETS AND

KUIPER BELT

Received

17 June 2013

Accepted

14 October 2013

Published

16 December 2013

Correspondence and requests for materials should be addressed to

M.I. (magnus. ivarsson@nrm.se)

\section{Fungal colonization of an Ordovician impact-induced hydrothermal system}

\author{
Magnus Ivarsson ${ }^{1}$, Curt Broman ${ }^{2}$, Erik Sturkell ${ }^{3}$, Jens Ormö ${ }^{4}$, Sandra Siljeström ${ }^{5,6}$, Mark van Zuilen ${ }^{7}$ \\ \& Stefan Bengtson'
}

'Department of Palaeobiology and Nordic Center for Earth Evolution (NordCEE), Swedish Museum of Natural History, Box 50007 SE-10405 Stockholm, Sweden, ${ }^{2}$ Department of Geological Sciences, Stockholm University, Sweden, ${ }^{3}$ Department of Earth Sciences, University of Gothenburg, Sweden, ${ }^{4}$ Centro de Astrobiologia, Instituto Nacional de Técnica Aeroespacial, Madrid, Spain,

${ }^{5}$ Department of Chemistry, Materials and Surfaces, SP Technical Research Institute of Sweden, Box 857, 50111 Borås, Sweden, ${ }^{6}$ Geophysical Laboratory, Carnegie Institution of Washington, 5251 Broad Branch Road, Washington DC 20015, USA, ${ }^{7}$ Equipe Géobiosphère, Institut de Physique du Globe de Paris - Sorbonne Paris Cité, Université, France.

Impacts are common geologic features on the terrestrial planets throughout the solar system, and on at least Earth and Mars impacts have induced hydrothermal convection. Impact-generated hydrothermal systems have been suggested to possess the same life supporting capability as hydrothermal systems associated with volcanic activity. However, evidence of fossil microbial colonization in impact-generated hydrothermal systems is scarce in the literature. Here we report of fossilized microorganisms in association with cavitygrown hydrothermal minerals from the 458 Ma Lockne impact structure, Sweden. Based on morphological characteristics the fossilized microorganisms are interpreted as fungi. We further infer the kerogenization of the microfossils, and thus the life span of the fungi, to be contemporaneous with the hydrothermal activity and migration of hydrocarbons in the system. Our results from the Lockne impact structure show that hydrothermal systems associated with impact structures can support colonization by microbial life.

(1) ydrothermal systems associated with volcanic activity in marine settings are known to support diverse ecosystems ${ }^{1}$. The fossil record further tells us that microbial life has existed in deep oceanic crust associated with hydrothermal activity throughout life's history on Earth ${ }^{2}$. It has been suggested that impactgenerated hydrothermal systems could have the same life supporting capability as hydrothermal systems associated with volcanic activity ${ }^{3}$, and that they could represent potential microbial habitats on Mars.

The presence of a deep subsurface biosphere has promoted a change of view regarding the distribution of life on Earth, which may have consequences for our understanding of habitability on other terrestrial bodies as well ${ }^{5,6}$. The main prerequisite of the subsurface biosphere is the presence of migrating fluids. In association with volcanic activity fluids are heated and form hydrothermal systems in which these fluids circulate and react with the host rock. The geochemical conditions in such environments are favourable for microbial metabolism and support colonization of non-photosynthetic, lithotrophic communities?.

The energy released at an impact is partly transformed into heat. Some of the heat leads to the production of impact melt, which may act as a heat source for hydrothermal convection. Impacts also result in deep fractures in the target, which initially provide pathways for water to flow through the rock. Hydrothermal systems can prevail in impact craters for thousands of years ${ }^{8}$, and for substantially longer periods (up to a million years) in large craters 9 . This is well enough time for microbes to colonize the systems. Hydrothermal mineral occurrences are abundant and have been identified in over a third of the $\sim 184$ confirmed impact craters found on Earth ${ }^{10}$. Remains of microbial colonization, however, are rare and inconclusive ${ }^{1-13}$. Confirmation of microbial colonization in impact-induced paleo-hydrothermal systems would substantially increase our understanding of impact structures as potential universal habitats ${ }^{14}$. On planetary bodies that are geologically inactive, which most known terrestriallike planets are, impact-generated hydrothermal systems could represent the only life supporting systems.

The Lockne impact crater, Sweden, is a concentric structure with an inner crater diameter of $7.5 \mathrm{~km}$ developed in the crystalline basement. The oldest post-impact sediments have been dated at $458 \mathrm{Ma}^{15}$. At the time of impact, the area was covered by a more than $500 \mathrm{~m}$ deep sea ${ }^{16}$. The target were the $1.86-1.85 \mathrm{Ga}$ Revsund granitoids ${ }^{17}$ and the $1250-1200 \mathrm{Ma}$ alkali and olivine-rich Åsby dolerite ${ }^{18}$ overlain by a sedimentary cover of Cambrian bituminous black mud (today alum shale) and Ordovician consolidated limestone. The bitumen-rich and marine target environment makes Lockne an ideal choice for this study, as it provides a source for aqueous fluids, means for fossil preservation and a potential analogue to warm-wet periods during the Martian geologic history. Even the occurrence of bitumen/ 
oil in the Lockne hydrothermal system ${ }^{19}$ may have parallels in the possible methane hydrate deposits below the Martian surface ${ }^{20}$.

\section{Results}

The samples used in this study have been collected from the drill core LOC1 (total length $225.15 \mathrm{~m}$ ), which is drilled at the north-western part of the Lockne impact structure (see ref. 38 for a map of the structure). The cored sequence comprises crystalline impact breccia and fractured basement rock, slump- and resurge deposits, and secular sediments. The samples were taken from veins and vugs in the brecciated basement rock that are partly filled with hydrothermally formed calcite and quartz and to minor extent with pyrite, chalcopyrite, galena and sphalerite (Fig. 1A). In a section between 171.30 and $219.90 \mathrm{~m}$ depth in the core, consisting of breccia and fractured rock, bitumen is abundant and associated with kerogenous matter that covers the hydrothermal minerals as a thin film. This film is a couple of micrometers thick and has a yellow-brownish appearance in optical microscopy (Fig. 1B). In ESEM the film has a black appearance (Fig. 1C), and EDS analyses shows that it consists exclusively of $\mathrm{C}$ and $\mathrm{O}$ with minor traces of $\mathrm{S}, \mathrm{Si}, \mathrm{Al}, \mathrm{Mg}, \mathrm{Fe}, \mathrm{Ca}$ and $\mathrm{K}$.

The C-rich film is associated with long, undulating and curvilinear filaments that are preserved as complex networks forming entangled, almost chaotic assemblages (Figs. 1B, D-G). These filaments are black in optical microscopy in contrast to the yellow-brownish film but have the same black appearance as the film in ESEM. The filaments originate in the C-rich film and extend into the networks. The networks further contain a high degree of trapped as well as precipitated minerals (chalcopyrite and pyrite), which makes them even more chaotic in appearance.
The filaments are 5-25 $\mu \mathrm{m}$ in diameter and up to one $\mathrm{mm}-$, in length, and their morphology is highly varied. They branch frequently, and anastomoses between branches are common (Figs. 2A, B). At places where the filaments follow the crystal planes of the euhedral quartz and calcite crystals, anastomoses between branches are distinct and easily observed (Fig. 2B).

The filaments occur both as smooth structures with no distinctive features (Figs. 2A, B), or with a bulgy surface, as well as twisted structures (Figs. 2C, D). Transitions between all types are common (Fig. 2E). Filaments also occur as parallel or twined assemblages, which sometimes makes them easily mistaken for a single filament (Fig. 2C, E). In most cases, the filaments appear coherent, but in a few places septa-like structures are visible. Figure $3 \mathrm{~F}$ shows how a filamentous structure has been cut at the place of a septum.

The chemical composition of the fossils was investigated by EDS, Raman spectroscopy, time-of-flight secondary ion mass spectrometry (ToF-SIMS) and for carbon stable isotopes. EDS analyses showed that the composition of the filamentous structures is similar to that of the C-rich film. Raman spectroscopy further showed that the fossils consist of disordered carbonaceous material (CM). In lowgrade metamorphic terrains CM shows a complex Raman spectrum that consists of several partially overlapping peaks (Fig. 3). The peaktemperature of alteration can be derived from the relationship RA1 $=0.0008 . \mathrm{T}+0.3758$ (where the ratio $\mathrm{RA} 1=(\mathrm{D} 1+\mathrm{D} 4) /(\mathrm{D} 1+\mathrm{D} 2$ $+\mathrm{D} 3+\mathrm{D} 4+\mathrm{G})^{21}$. From 17 individual Raman measurements on samples from the Lockne impact structure an average temperature of ca. $250^{\circ} \mathrm{C}$ was calculated (S1).

The $\delta 13 \mathrm{C}$ values of the fossilized filaments range from -22 to -30 $\%$ (PDB), which indicates carbon from an organic source. According
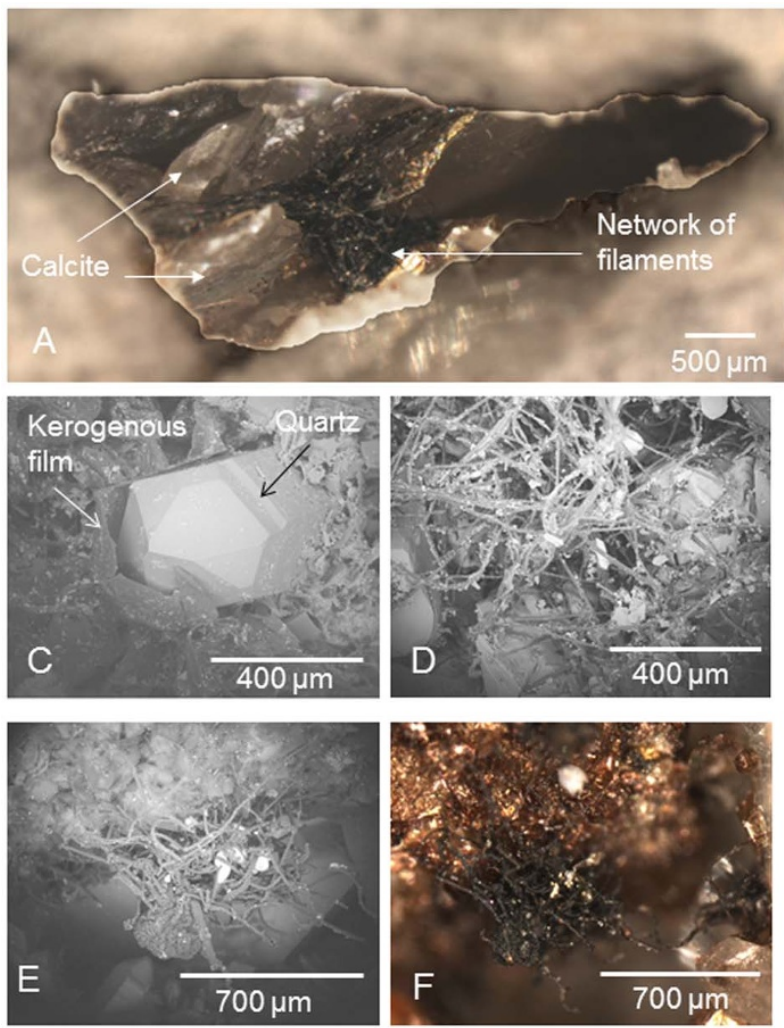
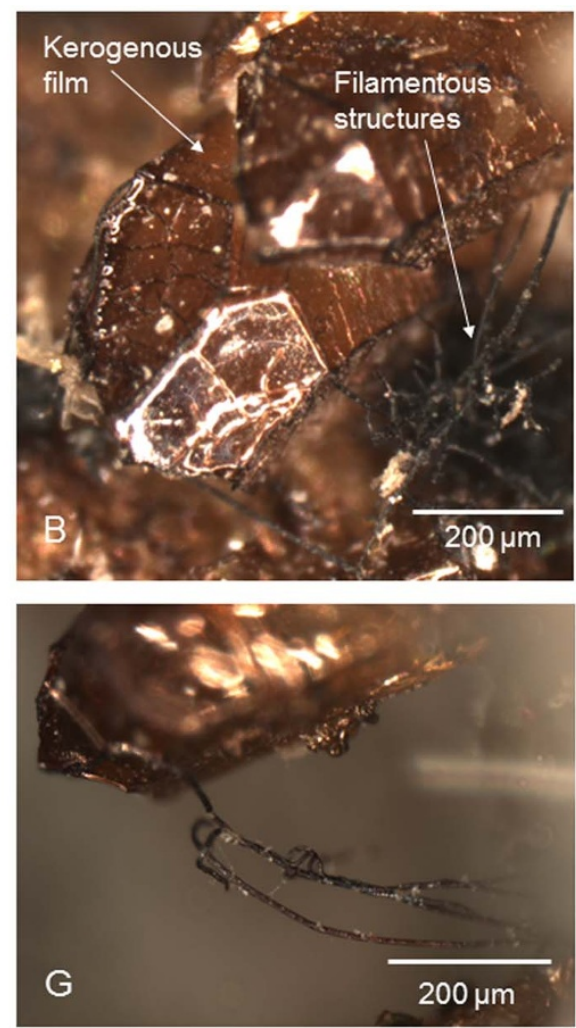

Figure 1 Microphotographs and ESEM images. (A) Microphotograph showing a cavity half filled with calcite and with a network of fossilized filaments attached to the mineral surfaces. The focus of the image is within the cavity. (B) Microphotograph of an euhedral calcite crystal covered in a yellowbrownish kerogenous film. Note the close association between the film and filamentous structures. (C) ESEM image of a quartz crystal where the kerogenous film has been removed from one side. (D) ESEM image of a network of filaments with incorporated mineral grains. (E) ESEM image of a network of filaments attached to one side of a vesicle. (F) Microphotograph of the network shown in E as comparison of the colour variations. (G) Closeup of filaments attached to a mineral surface. 

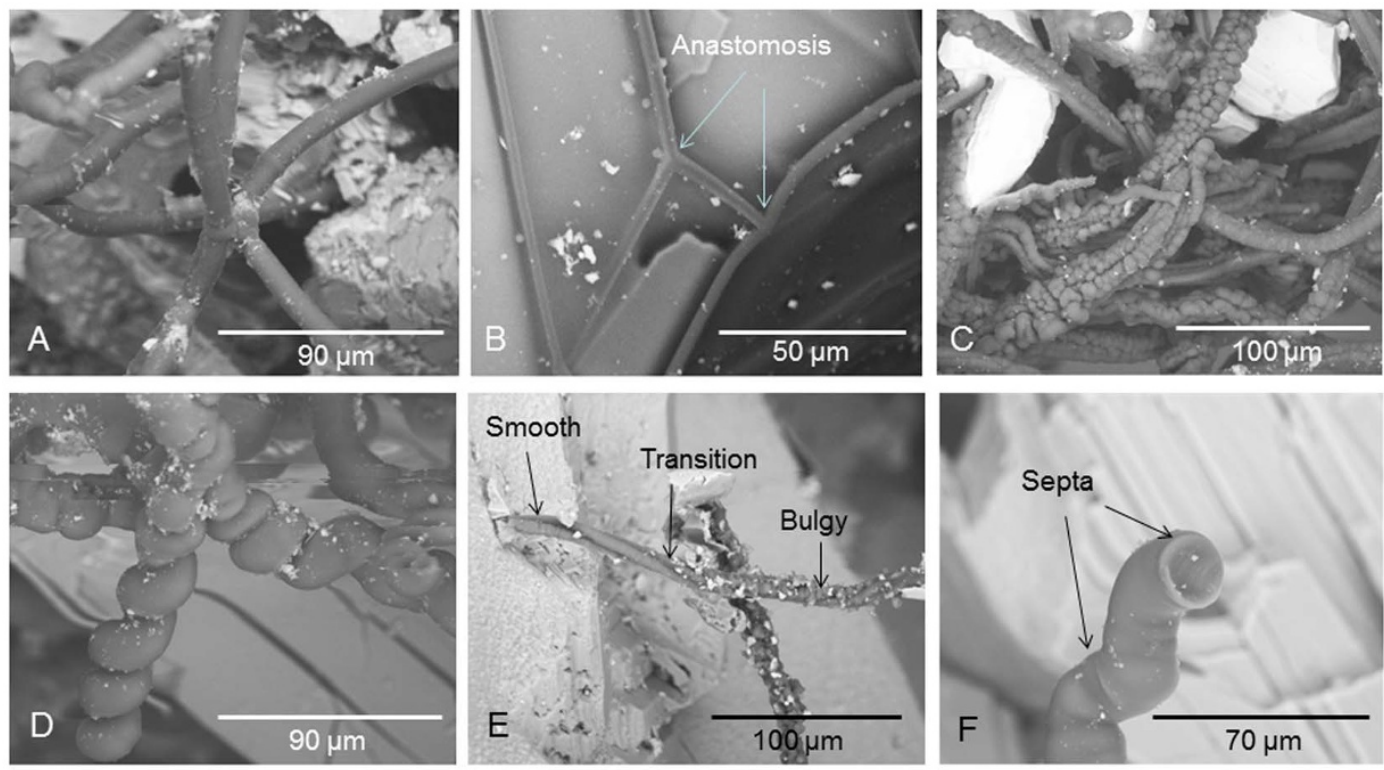

Figure $2 \mid$ ESEM images. (A) Branching filaments with a smooth surface. (B) Anastomoses between branches. (C) Filaments with bulgy, irregular surface occurring in twined assemblages. (D) Filaments with a twisted appearance. (E) Twined filaments that show the intersection where smooth surfaces of the filaments alter to more bulgy surfaces. (F) Repetitive septa. The filament is broken off at one septum.

to the NBS-22 standard the measured $\delta 13 \mathrm{C}$ values are consistent with $\delta 13 \mathrm{C}$ values for crude oil ${ }^{22}(\mathrm{~S} 2)$.

The positive ToF-SIMS spectra of the filamentous structures (Fig. 4) and kerogenous film (not shown) are similar and dominated by peaks from organics. They contain peaks from $\mathrm{m} / \mathrm{z} 77.04\left(\mathrm{C}_{6} \mathrm{H}_{5}\right)$ to at least $\mathrm{m} / \mathrm{z} 300.07\left(\mathrm{C}_{24} \mathrm{H}_{12}\right)$ (Fig. $4 \mathrm{E}$ ) which can be assigned to aromatic moieties ${ }^{23}$, and peaks from $\mathrm{m} / \mathrm{z} 57.08$ to $\mathrm{m} / \mathrm{z} 113.13\left(\mathrm{C}_{8} \mathrm{H}_{17}\right)$ (Fig. $4 \mathrm{G}$ ) which can be assigned to alkanes ${ }^{24-26}$. Both these compound classes are spatially resolved to the filaments as seen in Fig. 4A-F and are typically found in ToF-SIMS spectra of crude oils ${ }^{24-26}$. In the negative spectra of the filaments and films (not shown) there are peaks at $\mathrm{m} / \mathrm{z} 31.97$ (S) and 32.98 (HS), which are also typically found in spectra of crude oils. In addition, the negative spectra contain peaks, for example at m/z 62.97 and 78.96 which can be assigned to $\mathrm{PO}_{2}$ and $\mathrm{PO}_{3}$ and some intense peaks at $\mathrm{m} / \mathrm{z}$ at 409.30, 437.32, 451.34, 465.35, $479.39,493.40,535.43$ and 577.50 which have yet to be identified.

\section{Discussion}

To test the biogenicity of the present putative fossilized microorganisms we use the criteria by Ivarsson ${ }^{27}$, adapted for establishment of biogenicity of microfossils in crystalline basement: (1) is the geologic context compatible with life? (2) Is the putative microfossils indigenous

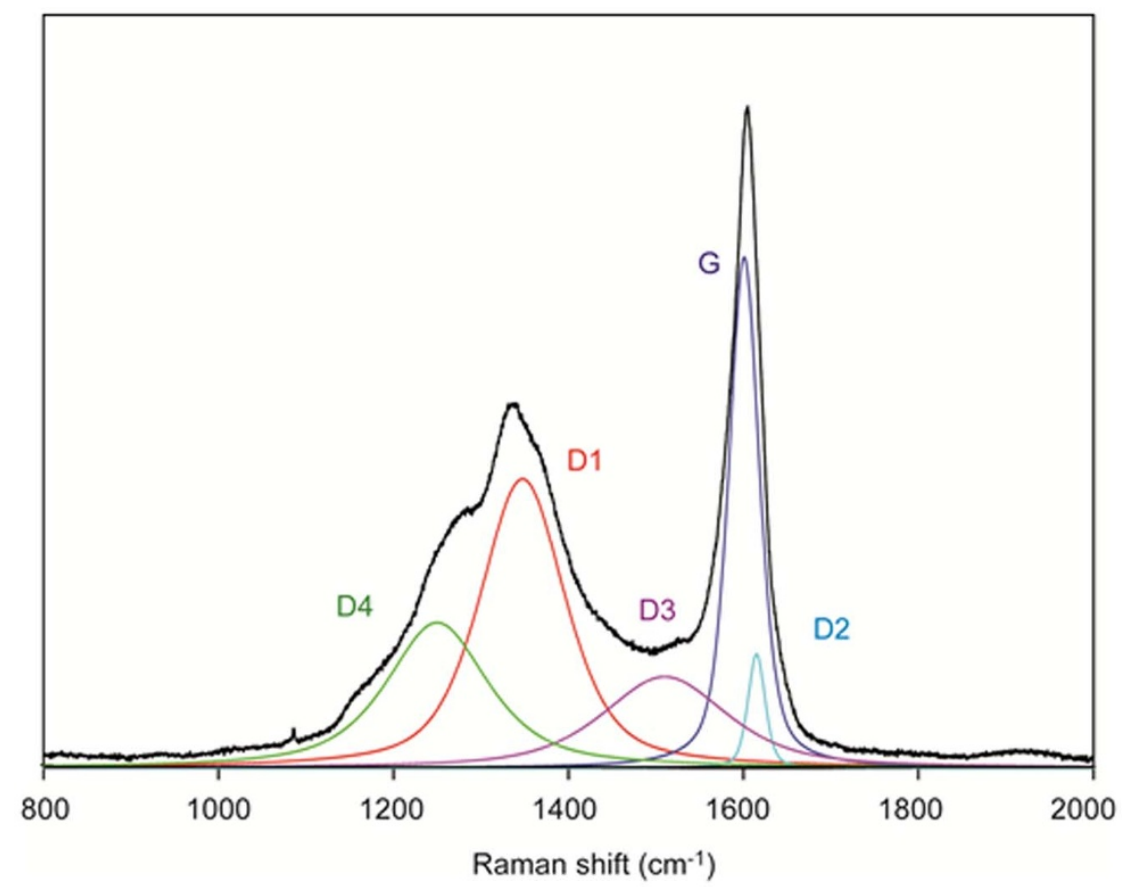

Figure 3 Raman spectrum of disordered carbonaceous material of a fossilized filament. The 'graphite'-related G-band $\left(1580 \mathrm{~cm}^{-1}\right)$ is caused by vibrations of hexagonal carbon ring structures, while the 'disorder'-related bands D1 $\left(1350 \mathrm{~cm}^{-1}\right)$, D2 $\left(1620 \mathrm{~cm}^{-1}\right)$, D3 $\left(\mathrm{ca} .1500 \mathrm{~cm}^{-1}\right)$ and D4 $\left(1250 \mathrm{~cm}^{-1}\right)$ are caused by defects. 

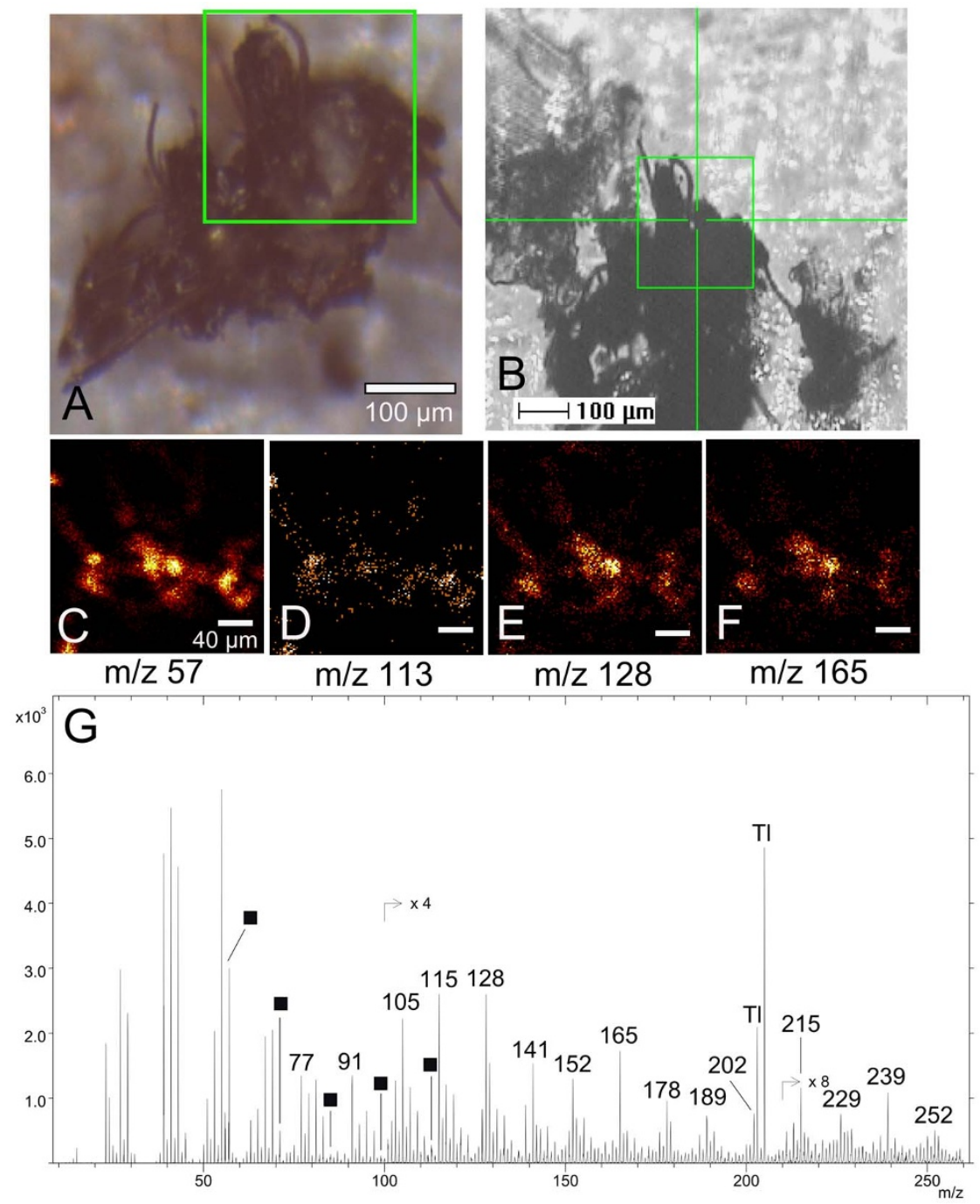

Figure 4 ToF-SIMS analysis of filamentous structures. (A) Micrograph of analysed filaments. (B) ToF-SIMS video images of same filaments. The green square indicates area $\left(233 \times 233 \mu \mathrm{m}^{2}\right)$ imaged in C-G. ToF-SIMS ion images of $(\mathrm{C}) \mathrm{m} / \mathrm{z} \mathrm{57.08,} \mathrm{(D)} \mathrm{m/z} \mathrm{113.13,} \mathrm{(E)} \mathrm{m} / \mathrm{z} 128.05$, and (F) $\mathrm{m} / \mathrm{z} 165.06$. (G) ToF-SIMS spectrum of imaged area in (B-F). Squares indicate peaks that can be assigned to alkanes at m/z $57.08\left(\mathrm{C}_{4} \mathrm{H}_{9}\right), 71.09\left(\mathrm{C}_{5} \mathrm{H}_{11}\right), 85.11\left(\mathrm{C}_{6} \mathrm{H}_{13}\right)$, $99.12\left(\mathrm{C}_{7} \mathrm{H}_{15}\right)$ and $113.13\left(\mathrm{C}_{8} \mathrm{H}_{17}\right)$ while numbers indicate peaks that can be assigned to aromatics at m/z m/z $77.04\left(\mathrm{C}_{6} \mathrm{H}_{5}\right) 91.05\left(\mathrm{C}_{7} \mathrm{H}_{7}\right), 115.05\left(\mathrm{C}_{9} \mathrm{H}_{7}\right)$, $128.05\left(\mathrm{C}_{10} \mathrm{H}_{8}\right), 141.06\left(\mathrm{C}_{11} \mathrm{H}_{9}\right), 152.05\left(\mathrm{C}_{12} \mathrm{H}_{8}\right), 165.06\left(\mathrm{C}_{13} \mathrm{H}_{9}\right), 178.06\left(\mathrm{C}_{14} \mathrm{H}_{10}\right), 189.05\left(\mathrm{C}_{15} \mathrm{H}_{9}\right), 202.06\left(\mathrm{C}_{16} \mathrm{H}_{10}\right)$ and $215.07\left(\mathrm{C}_{17} \mathrm{H}_{11}\right)$. Tl indicates peaks originating from thallium at $\mathrm{m} / \mathrm{z} 202.97$ and 204.98 .

to the rock (rather than being a modern contaminant)? Is the indigenous microfossil syngenetic with secondary minerals? (3) Does the sample contain evidence of microbiological morphology? (4) Do the fossil-like microstructures contain chemical remnants indicative of past life? Are any organic biomarkers present? (5) Is there evidence of structural remains of colonies or communities? (6) Is there evidence of biominerals?

(1) Subseafloor hydrothermal systems are known as environments where life thrives due to favourable conditions like heat, redox chemistry and a steady supply of energy, carbon and nutrients $^{1,2,5,7}$. Fractures in the rock where fluids circulate are used as conduits for microorganisms that migrate through and colonize the system. In Lockne, a low-temperature hydrothermal system was generated by the heat from the impact ${ }^{19}$. A coherent melt sheet was never produced at Lockne but the melt was scattered in the crater as impactites, thus, the hydrothermal system was characterized by local thermal anomalies. Fluid inclusions in quartz and calcite indicate a variable system with temperatures that ranged between $60^{\circ} \mathrm{C}$ and $210^{\circ} \mathrm{C}$. Calcite precipitate with increasing temperatures compared to most minerals, and the maximum temperatures represent occasional pulses of hotter fluids. The mean temperatures of the hydrothermal system were significantly lower than the estimated maximum temperatures. Thus, in general, the temperatures were well within the known limits for life $^{28}$. A water depth of approximately $500 \mathrm{~m}$ corresponds to a hydrostatic pressure of 50 bars, which is within known pressure limits for life $\mathrm{e}^{29}$.

The target area at impact consisted of $30 \mathrm{~m}$ Cambrian black mud with a high content of organic matter that was heated and thermally altered to liquid hydrocarbons at impact ${ }^{19}$. The impact structure worked as a trap for these hydrocarbons that migrated through the system during the hydrothermally active period $^{19}$. The presence of migrating hydrocarbons in the system would be an obvious source of energy for heterotrophs. Thus, the conditions of the Lockne hydrothermal system were compatible with life and acted, at the same time, as an excellent energy supply for microbial life.

(2) The EDS, Raman, ToF-SIMS and carbon isotope analysis gives a concordant image of the microfossils as completely kerogenized. To become impregnated with carbon the microfossils must have 
been soaked in liquid hydrocarbons long enough for the carbon to penetrate the microfossils and replace the initial elements. The preservation of the microfossils is similar in mode to the preservation of vertebrates and other organisms found in tar pits and oil shales ${ }^{30,31}$. Organisms that get trapped under such conditions become saturated with-, and, eventually, more or less completely replaced by hydrocarbons. Thus, the preservation of the organisms must have occurred while liquid hydrocarbons were present in the system, thus, during the hydrothermal active period $^{19}$. Migration of hydrocarbons diminished as the impactgenerated fractures were sealed by deposited minerals and the hydrothermal circulation ceased. After that, the hydrocarbons were transformed into solid bitumen. Raman analysis of solid bitumens has shown that the alteration temperature of the originally organic material never exceeded $300^{\circ} \mathrm{C}^{19}$. Our Raman spectra of the kerogenous material of the C-rich film indicate similar temperatures, of $250^{\circ} \mathrm{C}$, and indicate that the carbon of the C-rich film and the filamentous structures is related to the solid bitumen ${ }^{19}$.

The kerogenization of the microfossils constrains them to the migration of hydrocarbons in the system and thus to the hydrothermal activity that followed the impact event. The precipitation of sulphides in the filamentous networks also indicates that the microfossils were present during the hydrothermal activity. Considering the lack of a coherent melt sheet, the low temperatures, and the location of LOC1 at the margin of the crater where cold seawater probably penetrated the system easier compared to the central areas, it is probable to assume that the hydrothermal active period was relatively short. There are no estimates made of the hydrothermal longevity at Lockne but in similar impact craters like Kärdla, for instance, the hydrothermal system was estimated to last for a few thousands of years ${ }^{32}$. A similar time frame is likely for the hydrothermal system at Lockne including the introduction, lifetime and preservation of the present microorganisms.

Shortly after impact and subsequent hydrothermal activity the Lockne area was covered by Caledonian thrust nappes. This caused only a negligible influence on the hydrothermal overprinting ${ }^{19}$ and efficiently protected the impact structure, which allows us today to study these well preserved fossilized microorganisms.

(3) The investigated filaments are characterized by microbial-like morphologies and correspond to other filamentous microfossils from subsurface and subseafloor settings $s^{29,33,34}$. The dimensions and morphologies, including septa, anastomoses between branches, and mycelium-like networks, are further characteristic of fungi rather than filamentous prokaryotes ${ }^{35,36}$. The dimensions correspond to known sizes of fungi ${ }^{35,36}$, although, size is an unreliable criterion to discriminate between eukaryotes and prokaryotes. Actinomycetes, a prokaryotic group in which mycelia and anastomosis occur, have a diameter of 1$2 \mu \mathrm{m}$, thus the diameter between 5 and $25 \mu \mathrm{m}$ in combination with the occurrence of anastomosis is consistent with a fungal interpretation. The bulgy structure and the occurrence in twined assemblages are also common features among fungal hyphae but absent among filamentous prokaryotes.

(4) No chemical biomarkers indicative of life was detected. The mode of preservation by replacement of hydrocarbons has either erased all biomarkers or blocks the detection of such.

(5) The filamentous structures occur without exception in colony-like assemblages that resemble fungal mycelia.

(6) Biomineralization was not observed. One explanation can be the unusual mode of preservation.
All criteria are seldom possible to fulfil in a single study and should be regarded as guidance for a discussion ${ }^{27}$. Overall, the results are in favour of a biogenic rather than abiotic interpretation. The results are further in favour of a fungal interpretation rather than filamentous prokaryotes, thus, we suggest that the preserved communities consist of kerogenized fungal mycelia that lived while the impact-generated hydrothermal system was active. The fungi were probably introduced to the active hydrothermal system by downward migration of seawater some time after the resurge had filled the crater. Marine fungi are widely distributed in the world's oceans and are known to live in deep sea sediments, on the seafloor in association with hydrothermal vents ${ }^{37}$, and have also been found as fossils in drilled basalt samples from the seafloor crust ${ }^{34}$. However, the present study is, by far, the oldest remains of a subseafloor biosphere inhabited by eukaryotes.

Our study confirms that, irrespective of the type of heat source (magma or impact melt), hydrothermal systems provide the necessities for microbial life as we know it: heat, liquid water, nutrients and redox chemistry. Put in a planetary context our results show that impact craters can provide suitable environments where life may reside.

\section{Methods}

Samples. The filamentous structures were found between 171.30 and $219.90 \mathrm{~m}$ depth in the drill core. The entire fossiliferous section is thus $48.6 \mathrm{~m}$ in length. Nine samples were selected from this section at various depths. The selection was done with respect to abundance of cavities such as fractures and vugs, their size and depth, as well as where these were observed to contain filamentous structures. The fragile and exposed nature of the filamentous structures demanded relatively open vesicles, thus-, deep and narrow vugs and fractures were excluded. Each sample contained usually more than one cavity with filamentous structures. Table S3 lists the samples and sampling depths. The filamentous structures were found and studied under microscopy in situ in the drill core samples. For the ESEM analysis the cores were sawed to cubes a couple of centimetres in diameter. A few filamentous structures were removed with a forceps of stainless steel and placed on a plate with silver glue for ESEM and EDS analyses.

ESEM. An XL30 environmental scanning electron microscope (ESEM) with a field emission gun (XL30 ESEM-FEG) was used to analyse the minerals and the filamentous structures. The ESEM was equipped with an Oxford $\mathrm{x}$-act energy dispersive spectrometer (EDS), backscatter electron detector (BSE) and a secondary electron detector (SE). The acceleration voltage was 20 or $15 \mathrm{kV}$ depending on the nature of the sample. The instrument was calibrated with a cobolt standard. Peak and element analyses were made using INCA Suite 4.11 software. Since most EDS analyses were performed in situ and subject to variations in focal depth the EDS analyses should be regarded with caution. However, consistency throughout the analyses and similar results from analyses of filamentous structures removed and placed on silver glue indicate that the analyses are reliable.

Stable isotopes. For stable-isotope analysis the samples were combusted with a Carlo Erba NC2500 analyser connected via a split interface to reduce the gas volume to a Finnigan MAT Delta V mass spectrometer. From these measurements the reproducibility was calculated to be better than $0.15 \%$ for $\delta^{13} \mathrm{C}$ and $\delta^{15} \mathrm{~N}$. Carbon and nitrogen values were determined simultaneously when measuring the isotope ratios. The relative error was $<1 \%$ for both measurements.

Raman spectroscopy. The Raman spectra were obtained using a Horiba-Jobin Labram 800 HR Raman spectrometer and an Olympus BX41 petrographic microscope at the Centre for Geobiology, University of Bergen, Norway. All analyses were made through a $100 \times$ objective, using $514 \mathrm{~nm}$ excitation of an Ar-ion laser adjusted to an on-sample intensity of ca. $2.5 \mathrm{~mW}$. Raman acquisition was performed in "multi-window" mode with $2 \times 5$ seconds running time and a spectral range of $100-2000 \mathrm{~cm}^{-1}$, using an edge filter for $514 \mathrm{~nm}$ excitation wavelength at $100 \mathrm{~cm}^{-1}$ cut-off, a $100 \mu \mathrm{m}$ entrance slit, a $1800 \mathrm{l} / \mathrm{mm}$ grating, and an air-cooled $\left(-70^{\circ} \mathrm{C}\right) 1024$ $\times 256$ pixel CCD array detector. The obtained spectral data was treated with the software "Lab Spec version 5.58.25". Spectra were baseline-subtracted by automatic polynomial fitting in order to remove the background fluorescence. Subsequent peak fitting and characterization was performed by peak-de-convolution using a GaussLorentian function with 1000 iterations per fit.

ToF-SIMS. Prior to the ToF-SIMS analysis the filamentous structures and kerogenous films were extracted from the samples using cleaned tweezers (cleaned with p.a grade heptane, acetone and ethanol in that order), mounted on double-sticky tape on a steel block in a laminar flow hood and then directly analysed. The analysis of 
the samples were performed in a ToF-SIMS IV instrument (ION-TOF GmbH, Germany) by rastering a $25 \mathrm{keV} \mathrm{Bi}_{3}{ }^{+}$beam over an area of $200-300 \mu \mathrm{m}^{2}$ for $200-$ $300 \mathrm{~s}$. The analyses were done in both positive and negative mode at high mass resolution (bunched mode: $\mathrm{m} / \Delta \mathrm{m} \geq 3000$ at $\mathrm{m} / \mathrm{z} 30, \Delta \mathrm{l} \sim 5 \mu \mathrm{m}$ ) with a pulsed current of $0.1 \mathrm{pA}$. In addition spectra were collected in high spatial resolution mode (burst alignment mode: $\mathrm{m} / \Delta \mathrm{m} \sim 100-300, \Delta \mathrm{l}<1 \mu \mathrm{m}$ ) with a pulsed current of $0.048 \mathrm{pA}$. Reference spectra were obtained from the tape using the same analysis conditions as for the samples in bunched mode. As the samples acted as insulators, the surfaces were flooded with electrons for charge compensation during analysis.

1. Baross, J. A., Wilcock, W. S. D., Kelley, D. S., DeLong, E. F. \& Cary, S. C. The subsurface biosphere at mid-ocean ridges: issues and challenges. The subseafloor biosphere at mid-ocean ridges. 1-11 (American Geophysical Monograph, Washington DC, 2004)

2. Furnes, H. et al. Oceanic pillow lavas and hyaloclastites as habitats for microbial life through time-A review. Links between Geological Processes, Microbial Activities and Evolution of Life. 1-68 (Springer, Berlin, 2008).

3. Versh, E., Kirsimäe, K. \& Jõeleht, A. Development of potential ecological niches in impact-induced hydrothermal systems: The small-to-medium size impacts. Planet. Space Sci. 54, 1567-1574 (2006).

4. Osinski, G. R. et al. Impact-generated hydrothermal systems on Earth and Mars. Icarus 224, 347-363 (2012).

5. Amend, J. P. \& Teske, A. Expanding frontiers in deep subsurface microbiology. Palaeogeogr. Palaeoclimatol. Palaeoecol. 219, 131-155 (2005).

6. Trimarco, E., Balkwill, D., Davidson, M. \& Onstott, T. C. In situ enrichment of a diverse community of bacteria from $4-5 \mathrm{~km}$ deep fault zone in South Africa. Geomicrobiol. J. 23, 463-473 (2006).

7. Orcutt, B., Sylvan, J. B., Knab, N. J. \& Edwards, K. J. Microbial ecology of the dark ocean above, at, and below the seafloor. Microbiol. Mol. Biol. Rev. 75, 361-422 (2011).

8. Jǒeleht, A., Kirsimäe, K., Plado, J., Versh, E. \& Ivanov, B. Cooling of the Kärdla impact crater: II. Impact and geothermal modeling. Meteorit. Planet. Sci. 40, 21-33 (2005).

9. Ames, D. E., Watkinson, D. H. \& Parrish, R. R. Dating of a regional hydrothermal system induced by the 1850 Ma Sudbury impact event. Geology 26, 447-450 (1998).

10. Naumov, M. V. Impact-generated hydrothermal systems: data from Popigai, Kara, and Puchezh-Katunki impact structures. Impacts in Precambrian shields. 117-171 (Springer, Berlin, 2002).

11. Hode, T., Cady, S., von Dalwigk, I. \& Kristiansson, P. Evidence of ancient microbial life in an impact structure and its implications for astrobiology - a case study. From Fossils to Astrobiology. 249-273 (Springer, Netherlands, 2008).

12. Lindgren, P. et al. Putative fossil life in a hydrothermal system of the Dellen impact structure, Sweden. Int. J. Astrobiol. 9, 137-146 (2010).

13. Parnell, J. et al. Sulfur isotope signatures for rapid colonization of an impact crater by thermophilic microbes. Geology 38, 271-274 (2010).

14. Rathbun, J. A. \& Squyres, S. W. Hydrothermal systems associated with Martian impact craters. Icarus 157, 362-372 (2002).

15. Alwmark, C. \& Schmitz, B. Extraterrestrial chromite in the resurge deposits of the early Late Ordovician Lockne crater, central Sweden. Earth Planet. Sci. Lett. 253, 291-303 (2007).

16. Shuvalov, V., Ormö, J. \& Lindström, M. Hydrocode simulation of the Lockne marine target impact event. Impact Tectonics. 405-422 (Springer, Berlin, 2005).

17. Högdahl, K. 1.86-1.85 Ga intrusive ages of K-feldspar megacryst-bearing granites in the type area of the Revsund granites in Jämtland County, central Sweden. GFF 122, 359-366 (2000).

18. Lindström, M., Lundqvist, J. \& Lundqvist, T. Sveriges geologi från urtid till nutid. (Studentlitteratur, Lund, 2000).

19. Sturkell, E. F. F., Broman, C., Forsberg, P. \& Torssander, P. Impact-related hydrothermal activity in the Lockne impact structure, Jämtland, Sweden. Eur. J. Min. 10, 589-606 (1998)

20. Gainey, S. R. \& Elwood Madden, M. E. Kinetics of Methane Clathrate Formation and Dissociation Under Mars Relevant Conditions. Icarus 218, 513-524 (2012).

21. Lahfid, A. et al. Evolution of the Raman spectrum of carbonaceous material in low-grade metasediments of the Glarus Alps (Switzerland). T. Nov. 22, 354-360 (2010).

22. Sharp, Z. Principles of stable isotope geochemistry. (Pearson Education. Upper Saddle River, 2007).
23. Stephan, T., Jessberger, E. K., Heiss, C. H. \& Rost, D. TOF-SIMS analysis of polycyclic aromatic hydrocarbons in Allan Hills 84001. Meteor. Planet. Sci. 38, 109-116 (2003).

24. Siljeström, S. et al. Detection of organic biomarkers in crude oils using ToF-SIMS Org. Geochem. 40, 135-143 (2009).

25. Thiel, V. \& Sjövall, P. Using Time-of-Flight Secondary Ion Mass Spectrometry to Study Biomarkers. Annual Review of Earth and Planetary Sciences, DOI:10.1146/ annurev-earth-040610-133525 (2010).

26. Siljeström, S. Single fluid inclusion analysis using ToF-SIMS: Implications for ancient Earth biodiversiy and paleoenvironment studies $\mathrm{PhD}$ thesis, (Stockholm University, 2011).

27. Ivarsson, M. Advantages of doubly polished thin sections for the study of microfossils in volcanic rock. Geochem. Transact. 7, 5 (2006).

28. Kashefi, K. \& Lovley, D. R. Extending the upper temperature limit for life. Science 301, 934 (2003)

29. Ehrlich, H. L. Geomicrobiology. (Dekker, New York, 1996).

30. Franzen, J. L. Exceptional preservation of Eocene vertebrates in the lake deposit of Grube Messel (West Germany). Phil. Trans. R. Soc. Lond. B311, 181-186 (1985).

31. Shaw, C. A. How the fossils were preserved. Rancho La Brea, Death Trap and Treasure Trove. Terra 38, 51 (2001).

32. Naumov, M. V. Principal features of impact-generated hydrothermal circulation systems: mineralogical and geochemical evidence. Geofluids 5, 165-184 (2005).

33. Hofmann, B. A., Farmer, J. D., von Blanckenburg, F. \& Fallick, A. E. Subsurface filamentous fabrics: an evaluation of origins based on morphological and geochemical criteria, with implications for exopaleontology. Astrobiology 8 87-117 (2008).

34. Ivarsson, M., Bengtson, S., Skogby, H., Belivanova, V. \& Marone, F. Fungal colonies in open fractures of subseafloor basalt. Geo-Mar. Lett. 33, 233-243 (2013).

35. Deacon, J. W. Modern mycology. (Wiley Blackwell, Oxford, 1997).

36. Webster, J. \& Weber, R. W. S. Introduction to fungi. (Cambridge University Press, Cambridge, 2007)

37. Nagano, Y. \& Nagahama, T. Fungal diversity in deep-sea extreme environments. Fung. Ecol. 5, 463-471 (2012).

38. Broman, C., Sturkell, E. \& Fallick, A. E. Oxygen isotopes and implications for the cavity-grown quartz crystals in the Lockne impact structure, Sweden. GFF 133, 101-107 (2011).

\section{Acknowledgments}

We wish to thank Heike Siegmund at the Department of Geological Sciences, Stockholm University, for the stable isotope analysis and Per Andersson at the Laboratory for Isotope Geology (LIG), Swedish Museum of Natural History, for discussions about isotope geochemistry. Marianne Ahlbom at the Department of Geological Sciences, Stockholm University, is acknowledged for the ESEM/EDS analysis. Funding was provided by the Deep Carbon Observatory (sub award to PI Andrew Steele), the Postdoctoral fellowship program of Geophysical Laboratory, Carnegie Institution of Washington and the Swedish National Space Board (Contract No. 83/10 and 121/11)

\section{Author contributions}

M.I. and C.B.: Designed experiment and sampled the drill core. E.S. and J.O.: Conducted field work and organized drilling. S.S.: Conducted and interpreted ToF-SIMS data. M.V.Z. performed, processed and interpreted the Raman spectroscopy data. M.I., C.B. and S.B.: Interpreted data and wrote paper.

\section{Additional information}

Supplementary information accompanies this paper at http://www.nature.com/ scientificreports

Competing financial interests: The authors declare no competing financial interests. How to cite this article: Ivarsson, M. et al. Fungal colonization of an Ordovician impact-induced hydrothermal system. Sci. Rep. 3, 3487; DOI:10.1038/srep03487 (2013).

This work is licensed under a Creative Commons AttributionNonCommercial-NoDerivs 3.0 Unported license. To view a copy of this license, visit http://creativecommons.org/licenses/by-nc-nd/3.0 